\title{
Advances in preimplantation genetic diagnosis/screening
}

\author{
YAN LiYing ${ }^{1,2,3 \dagger}$, WEI Yuan ${ }^{1,2,3 \dagger}$, HUANG Jin ${ }^{1,2,3}$, ZHU XiaoHui ${ }^{1,2,3}$, SHI XiaoDan ${ }^{1,2,3}$, \\ XIA Xi ${ }^{1,2,3}$, YAN Jie ${ }^{1,2,3}$, LU CuiLing ${ }^{1,2}$, LIAN Ying ${ }^{1,2,3}$, LI Rong ${ }^{1,2,3}$, \\ LIU Ping ${ }^{1,2,3} \&$ QIAO Jie ${ }^{1,2,3 *}$ \\ ${ }^{1}$ Department of Obstetrics and Gynecology, Peking University Third Hospital, Beijing 100191, China; \\ ${ }^{2}$ Key Laboratory of Assisted Reproduction, Ministry of Education, Beijing 100191, China; \\ ${ }^{3}$ Beijing Key Laboratory of Reproductive Endocrinology and Assisted Reproduction, Beijing 100191, China
}

Received April 9, 2014; accepted April 28, 2014; published online June 6, 2014

\begin{abstract}
Preimplantation genetic diagnosis (PGD) gives couples who have a high risk of transmitting genetic disorders to their baby the chance to have a healthy offspring through embryo genetic analysis and selection. Preimplantation genetic screening (PGS) is an effective method to select euploid embryos that may prevent repeated implantation failure or miscarriage. However, how and to whom PGS should be provided is a controversial topic. The first successful case of PGD of a human being was reported in 1990, and there have been tremendous improvements in this technology since then. Both embryo biopsy and genetic technologies have been improved dramatically, which increase the accuracy and expand the indications of PGD/PGS.
\end{abstract}

preimplantation genetic diagnosis, preimplantation genetic screening, indications, biopsy methods, array comparative genomic hybridization, next-generation sequencing

Citation: Yan LY, Wei Y, Huang J, Zhu XH, Shi XD, Xia X, Yan J, Lu CL, Lian Y, Li R, Liu P, Qiao J. Advances in preimplantation genetic diagnosis/screening. Sci China Life Sci, 2014, 57: 665-671, doi: 10.1007/s11427-014-4683-5

Preimplantation genetic diagnosis (PGD) is an established reproductive option for couples with a risk of conceiving a baby that is affected with some known genetic disease to have an unaffected child, avoiding the termination of pregnancy or recurrent miscarriages. PGD is useful in the diagnosis of a variety of genetic disorders that are caused by a known single gene mutation and chromosome number or structure abnormalities, which can be detected in a single cell.

Since 1990, when the first live birth following PGD for a recessive $\mathrm{X}$ chromosome-linked disease was reported [1], PGD has been routinely applied in a variety of genetic disorders, including Tay-Sachs disease, sickle cell anemia, and thalassemia, as well as predicting cancer predisposition

$\dagger$ Contributed equally to this work

*Corresponding author (email: jie.qiao@263.net)
[2-4]. The most frequent single gene disorders detected by PGD are beta-thalassemia, cystic fibrosis, myotonic dystrophy, Huntington disease, fragile $\mathrm{X}$ syndrome [5], Comel-Netherton syndrome [6], and endocrine diseases (including persistent hyperinsulinemic hypoglycemia of infancy, congenital adrenal hyperplasia, and multiple endocrine neoplasia type 2A) [7]. Currently, over 10000 babies have been born by PGD and preimplantation genetic screening (PGS) worldwide [8].

In the last 20 years, PGD technology has made a series of steps that have improved its accuracy and specificity and allowed broader applications for a variety of genetic diseases. There are now multiple biopsy methods for PGD at different embryonic development stages with unique advantages. Strategies such as whole-genome amplification (WGA) have overcome the limitations of minimal template DNA from a single biopsied cell. Multiple genes can now 
be assessed simultaneously, and the accuracy of the method has been improved.

Herein, we reviewed the indications of PGD/PGS recent changes in genetic analysis, biopsy methods, WGA methods, array platforms and the application of next-generation sequencing (NGS) to PGD/PGS programs (Figure 1).

\section{Indications for the application of PGD/PGS}

\subsection{PGD for single gene mutations and chromosomal disorders}

PGD allows patients who are carriers or who are affected by genetic diseases to select unaffected embryos for transfer before pregnancy [9]. Single-gene diseases were originally the first indication for PGD and aimed to perform genetic testing and establish only unaffected pregnancies [1]. Today, PGD remains a valid alternative for couples at high risk of having a child with monogenetic diseases, i.e., cystic fibrosis, beta-thalassemia, Huntington disease, and myotonic dystrophy [1,10]. In Europe, more than 7000 cycles were performed for single-gene disorders in a total of 60 centers until 2010 [11]. Additionally, PGD can help carriers with structural chromosome abnormalities, such as reciprocal and Robertsonian translocations, inversions, deletions, and insertions, have a baby with a normal chromosome balance [12].

\subsection{PGD for cancer patients with a susceptibility gene}

Individuals carrying gene mutations predisposing them to hereditary breast/ovarian cancer have concerns about passing these health problems to their future children [13]. It is now feasible to use PGD during the process of in vitro ferti- lization (IVF) to screen genes associated with high cancer risk. Once the mutation site is identified, patients can use PGD to select an embryo without familial cancer-predisposing mutations. This procedure has already been performed for several cancers, including the common syndromes of genetic predisposition to breast cancer [14] and neurofibromatosis type 1 [15].

Drusedau et al. [16] described a universal single-cell PGD test for carriers with BRCA1/2 (breast cancer 1/2) mutations based on haplotyping 6 (BRCA1) and 8 (BRCA2) microsatellite markers in a multiplex polymerase chain reaction (PCR), which have a clinical pregnancy rate of $23.5 \%$ per embryo transfer. Malcov et al. [17] reported that 48 PGD cycles in 14 couples resulted in eight pregnancies with the cancer predisposition mutation and flanking polymorphic markers according to single-cell multiplex nested PCR, which confirmed that PGD of cancer predisposition genes is a feasible and reliable procedure that is especially suitable for infertile carrier couples. More discoveries of cancer predisposition mutations will increase the demand for PGD to prevent the transmission of disease-related mutations to the next generation.

\subsection{PGD for mitochondrial diseases}

About $15 \%$ of mitochondrial or oxidative phosphorylation diseases are caused by maternally inherited mitochondrial DNA (mtDNA) mutations. Approximately one in 4000 children are born with an inherited mitochondrial disease in the United States [18]. Because of the severe phenotype, the limited effective treatments, and the high recurrence risk in the offspring of carrier females, couples with this high risk often wish to prevent the transmission of these mtDNA disorders to their babies. PGD provides an option to prevent

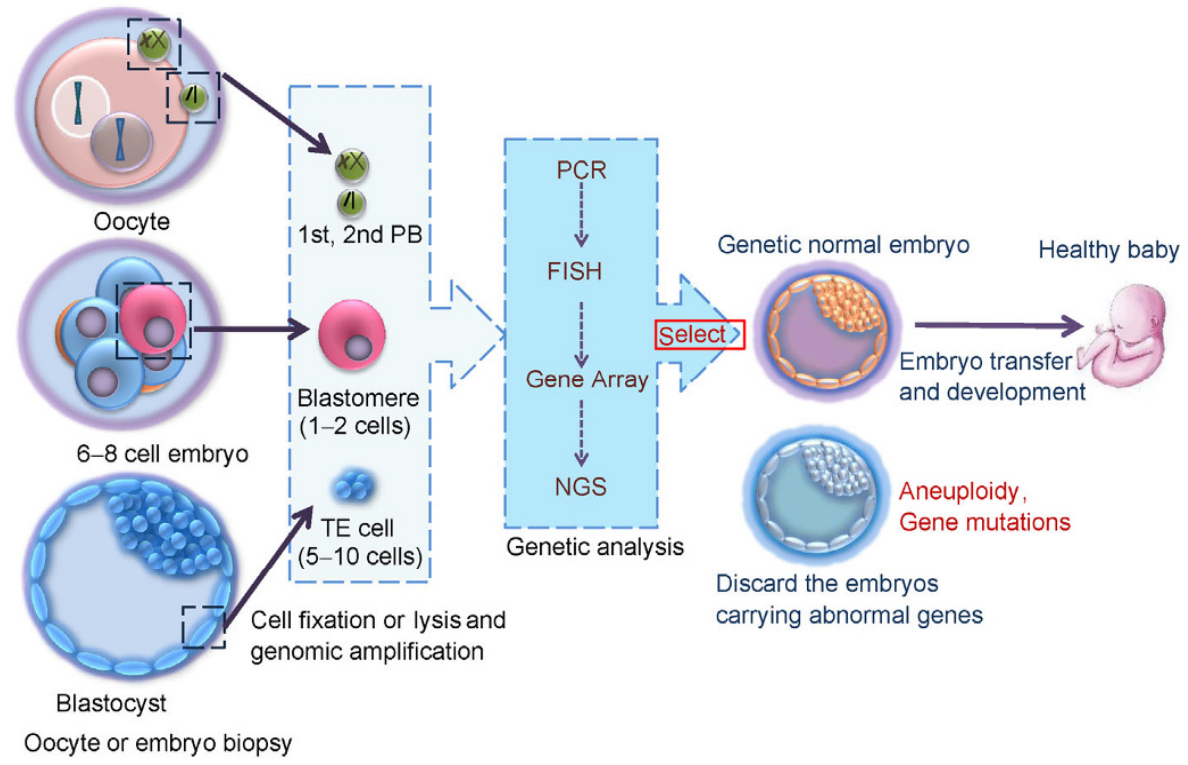

Figure 1 PGD procedures for patients at high risk of transmitting genetic disorders to their baby. 
the transmission of mtDNA disorders by transferring an embryo below the threshold of clinical expression [19].

The successful clinical application of PGD of mtDNA diseases has been reported in some studies. Steffann et al. [20] found that the variation of mitochondrial heteroplasmy was fairly small among blastomeres from each embryo but the mutation load widely varied among embryos (from zero to $100 \%)$. They carried out PGD of an mtDNA mutation $(8993 \mathrm{~T}>\mathrm{G})$ carrier mother who already had an affected child; PGD resulted in a singleton pregnancy with delivery of a healthy child. Treff et al. [21] found that, for a carrier with $35 \%$ 3243A $>$ G mtDNA mutation load, the variation in the mutation load within and among embryos varied from $9 \%$ to $90 \%$ in oocytes and $7 \%$ to $91 \%$ in embryos, and the mutation loads in the trophectoderm could be predictive of the inner cell mass. These researchers selected a male embryo with a $12 \%$ mutation load in trophectoderm cells for transfer, resulting in the delivery of a boy with tissue-specific mutation loads ranging from undetectable to $15 \%$. Suzanne et al. [22] showed that PGD of mtDNA disorders was useful when there were oocytes below the threshold of the carriers and that the blastomere could be representative of the whole embryo in most cases. In this study, a healthy son was born from an m.8993T $>$ G carrier, which confirmed the possibility of conceiving healthy offspring from those couples with mtDNA diseases. Despite the above successful case reports, PGD has limited efficacy in predicting mtDNA disease because of heteroplasmy and genetic bottleneck. PGD may only reduce, but not eliminate, the risk of transmitting abnormal mtDNA in subsequent generations, and couples should be informed of this during the counseling.

For women with homoplasmic or high levels of heteroplasmic mtDNA mutations, oocyte donation is currently the only option to have a healthy child. However, oocyte donation is limited in that there is no genetic link to the mother with mtDNA mutations.

Two other promising approaches, pronuclear and spindle transfer, have emerged recently that could be used to avoid mitochondrial disease. No successes have been reported in human until now. Only one group has reported embryonic stem cells derived from a blastocyst embryo by spindle transfer [23]. The safety of these technologies requires further evaluation.

\subsection{PGD for human leukocyte antigen (HLA) matching}

The use of PGD for combined analysis of mutations and HLA matching was reported for the first time in 2001 [24]. It enables the birth of an unaffected child with the closest HLA match to his (her) affected sibling. As a donor, the newborn baby could provide stem cells or some human tissue to the sibling in the transplant [25]. Numerous families have successfully used PGD for HLA matching to treat the affected child. In 2004, a group from Israel reported the successful cord blood transplantation to a Fanconi anemia patient from his HLA-matched sibling, who was born after PGD that included mutation analysis for Fanconi anemia and HLA typing [26].

Based on the data from the European Society of Human Reproduction and Embryology, more than 500 PGD-HLA cycles have been performed until October 2010 [11]. The most common indication of HLA-matching is PGD combined with the exclusion of $\beta$-thalassemia and/or sickle-cell syndromes ( $66 \%$ of cycles performed) [11].

\subsection{PGS for couples with a special history}

Because the first deliveries after embryo transfer following PGS were reported in 1995 [27], the procedure and technologies for aneuploidy detection have become readily available for clinical practice. Most of the early pregnancy losses are believed to be attributed to aneuploidy [28]. At present, PGS can be offered to couples with one or more of the following indications: (i) the woman with advanced maternal age ( $>35$ and $<40$ years), (ii) a history of recurrent miscarriage (two occurrences or more), (iii) repeated implantation failure (more than three occurrences), and (iv) severe male factor infertility [29]. With the development of chromosome screening methods, blastocyst freezing, and trophectoderm biopsy techniques, women with advanced maternal age ( $>35$ years of age) can use single-embryo screening for transfer to increase the birth rate [30]. Despite the above advances, problems still remain, such as how to optimize the procedure to safely offer the technique to patients and which group of patients would benefit more from routine biopsy [31].

\section{Genetic analysis methods in PGD}

\subsection{PGD using PCR}

Single-cell PCR was the first application used in PGD for two couples with a risk of transmitting adrenoleukodystrophy and X-linked mental retardation. Through DNA amplification of a Y chromosome-specific sequence, the female patients were confirmed to carry normal female twins [1]. Since then, the PCR method has been used to diagnose many single gene diseases during assisted reproductive technology processes.

However, using PCR for PGD also has difficulties such as contamination, amplification failure because of lowquantity DNA template, and allele drop-out (ADO) in heterozygous loci [32]. To obtain a more accurate diagnosis and simultaneously exclude ADO and contamination, the co-amplification of several loci by multiplex PCR is recommended [33,34]. Two upstream and two downstream markers are preferably applied within $1 \mathrm{Mb}$ of the disease mutation to reduce the risk of recombination events. If there are no linked markers available and the multiplex PCR is 
difficult, an alternative method to identify ADO is to biopsy two cells on day 3 or two cell clusters on day 5 with independent analysis [35-37].

\subsection{PGD/PGS using fluorescence in situ hybridization (FISH)}

The applications of FISH made the analysis of aneuploidies in embryos a reality. Screening a large number of chromosomes significantly increases the live-birth rate for mothers with an advanced maternal age [38]. The major limitations of FISH are the limited number of tested chromosomes that can be analyzed simultaneously and the technical difficulty of nuclear fixation and staining. Poor spreading could result in low-quality nuclei staining or even the loss of chromatin, decreasing the accuracy of the diagnosis [39,40]. Indeed, misdiagnosis can also result from overlapping signals, split signals, cross-hybridization, and polymorphisms [41]. However, some of these limitations might be overcome by using different strategies. To improve FISH accuracy, additional probes in the same chromosome could be applied to double-check ambiguous signals [42].

\subsection{Array comparative genomic hybridization (CGH) and single nucleotide polymorphism (SNP) applications in PGD or PGS}

In recent years, several approaches for 24-chromosome analysis coupled with WGA have been developed to improve clinical outcomes. The first of these approaches to be applied in PGS was CGH [43], in which the genome of the interested cell is hybridized with a reference genome on a slide. More recently, array CGH has emerged, which provides high resolution and a rapid and simple procedure. There are two types of array platforms: CGH and SNP [44]. The advances of the array platforms could increase the reliability and stability of diagnosis by PGS, but the approaches need to be optimized for future applications.

The first successful application of array CGH using single cells, such as a single lymphoblast, fibroblast, and blastomere [45], suggested that it was the most appropriate method because of its high efficiency, chromosome detection, and time of analysis. Simpson et al. also pointed out that array $\mathrm{CGH}$ was the preferred diagnostic approach to assess 24 chromosomes for genetic screening in IVF treatment [46].

\subsection{Next-generation sequencing (NGS) in PGD or PGS}

Current approaches to evaluate the genomic state in PGD have significant limitations, such as providing limited resolution or restricted information (PCR for some loci, FISH for a few chromosomes, array for aneuploidy screening), which prevent the detection of aneuploidy and SNPs associated with Mendelian diseases and de novo mutations [47].
Therefore, it is necessary to establish a straightforward and reliable approach that can simultaneously analyze all mentioned PGD/PGS indications. Advances in WGA and DNA sequencing have made it practical to generate huge amounts of data by high-throughput NGS technologies.

The first study reported the extensive preclinical validation and assessed the accuracy of NGS-based comprehensive aneuploidy screening with single cells. In this study, NGS was demonstrated as a robust high-throughput methodology ready for clinical application in reproductive medicine, with the potential advantages of reduced costs and enhanced precision [48].

Genomics analysis in PGD/PGS using NGS, microarrays, or real-time PCR is often limited by the small amount of template available, which could rely on WGA from a single cell to generate enough DNA template for sequencing. Multiple displacement amplification could provide improvements over PCR-based methods [49], but it still has considerable bias.

A group from Harvard University developed a new WGA method, multiple annealing and looping-based amplification cycles (MALBAC), which showed high uniformity across the genome and achieved $93 \%$ genome coverage for a single human cell at $25 \times$ mean sequencing. MALBAC has been used to sequence a single circulating tumor cell [50], single sperm cells [51], and single oocyte cells [52].

Hou et al. [52] estimated the sensitivity and specificity of aneuploidy detection with different resolutions and showed that, for sub-megabase resolution $(0.5 \mathrm{Mb})$, single-cell sequencing based on MALBAC achieves $94.8 \%$ sensitivity and $97.5 \%$ specificity, which is superior to most of the available CGH and SNP array technologies and allows accurate and cost-effective embryo selection for IVF. With MALBAC's significantly improved coverage uniformity [53], maternal point mutations can be detected with high sensitivity and accuracy. This approach can be applied to both polar bodies and blastocyst stage embryos, and it can detect all aneuploidies and gene mutations. Further improvements in the technology robustness and workflow, as well as finding new ways to reduce costs, will promote the use of NGS in clinical diagnosis. Eventually, the advantages of NGS will benefit PGD/PGS patients [54].

Perhaps many people want to use PGD to select embryos with a desired phenotype. In 2007, scientists in Europe identified the SNPs that are associated with a host of physical traits such as eye color, hair color, and freckles [55]. Currently, most clinics do not offer PGD for these features; however, from a technological point of view, it is a possible application in the future [25].

The authors believe that PGD should only be provided to couples with genetic diseases or a known serious disease, but not to anyone who expects a "designer baby." PGD technologies require development to a high level to achieve 
this goal. First, currently we cannot determine the relationship between most genotypes and phenotypes and the role of certain genotypes in human evolution. Second, we cannot distinguish the bad from the good genes in human beings. Third, PGD methods are performed on embryos in vitro; even using the so-called non-invasive technology, the long-term safety of this technology is still a concern. Therefore, PGD techniques cannot be used for "designer babies." Governments should develop strict laws and regulations to prevent the abuse of this technology.

\section{Cell samples provided for PGD}

The first step in preimplantation genetic testing is to obtain DNA from the oocyte or embryo. Currently, there are three potential methods according to the source of DNA collection: polar body biopsy, blastomere biopsy (aspiration) from the 6- to 8-cell cleaving embryos, and trophectoderm biopsy from the blastocyst. The optimal biopsy stage should be carefully considered.

The oocyte genotype can be deduced by analyzing the first and second polar body [52]. Polar body biopsy is less invasive and requires a longer time for the analysis than other methods, but it cannot be used to detect aneuploidies and mutations or aneuploidies inherited from the father and de novo mutations arising from mitosis.

Embryo biopsy is a more widely used approach because both paternal and maternal alleles can be detected. Embryo biopsy at the cleavage stage (6- to 8-cell stage) with the removal of one or two cells is the most common approach for PGD, which provides adequate samples but is detrimental to the embryo. About two of every five reproductively competent embryos will lose their ability to develop [56].

Blastomeric analysis is prone to error due to high ADO and mosaicism [57,58]. Blastocyst biopsy has been widely applied in PGD clinics in recent years because it is highly effective for the PGD of monogenic diseases [59]. Current data suggest that trophectoderm biopsy may not adversely impact embryos. In addition, blastocyst biopsy provides primary DNA templates, which would improve the sensitivity and specificity of PGD. However, the time for molecular diagnosis is limited. Thus, blastocyst freezing would be necessary. Fortunately, clinical outcomes indicated that fresh IVF and cryopreserved embryo transfer cycles were equivalent [59]. Currently, the blastocyst stage is the optimal stage to perform biopsies for preimplantation genetic testing $[56,60]$.

As for PGD with sperm, a group from France recently reported the first birth originating from couples with a male translocation carrier. By discontinuous gradient centrifugation, the proportion of unbalanced spermatozoa decreased from $63.6 \%$ to $52.3 \%$ in this patient [61].

\section{Misdiagnosis by PGD}

Notably, it is important to note that PGD is not as accurate as prenatal testing with chorionic villi sampling, amniocentesis, or testing of umbilical cord blood. Therefore, each patient must receive follow-up care, and are recommended prenatal diagnosis.

The causes of misdiagnosis include confusions of embryo and sample number (marking error, unclear, erased), the wrong embryo for transfer or thawing, maternal (cumulus cells) or paternal (sperm) contamination, ADO (one study reported $11.9 \%$ [62]), using incorrect and inappropriate probes or primers, probe or primer failure, and chromosomal mosaicism in cleavage-stage and blastocyst embryos. Unprotected sexual intercourse has been mentioned as a cause of adverse outcomes not related to PGD analysis errors [63]. The majority of these causes could be prevented by improved procedures, such as careful operation, double-check, sufficient pre-experimentation, and establishing a standard operation procedure. However, an exact diagnosis from a single cell is still a great challenge, and the risk of misdiagnosis cannot be completely eliminated.

The data collected by the European Society of Human Reproduction and Embryology (ESHRE) PGD Consortium indicated that the misdiagnosis was $0.15 \%$ for PCR-based cycles and $0.06 \%$ for FISH-based PGD cycles. However, these numbers may not reflect the reality. For example, some embryo transfer cycles have no follow-up records (no pregnancy or birth), and the majority of untransferred surplus embryos were not re-analyzed [11].

\section{Pregnancy rate with PGD}

The average pregnancy rate per oocyte retrieval cycle was about $23.04 \%$ (range, 0 to $100 \%$ ) according to the 12 th annual data from the ESHRE PGD Consortium [11]. Research about the PGD of monogenic diseases showed that the pregnancy rate per oocyte retrieval cycle reached $60 \%$ with an implantation rate of 50\% [59]. Another group obtained a clinical pregnancy rate of $60.3 \%$ per transfer cycle with an implantation rate of $53.5 \%$ [64].

\section{Summary}

Reproductive medicine, a quickly developing field of medicine, is the discipline that can directly apply most of the advances from genomics to clinical treatment by providing effective strategies for personalized fertility and sterility treatment. PGD represents a valuable option for patients with the high risk of transmitting an inherited disorder to their offspring. PGD can be applied for any Mendelian disorder with known locations. Moreover, combined with linkage marker (short tandem repeats, SNPs, and haplotypes) 
analysis, PGD can also be used if the mutation site is unknown. So far, more than 300 different conditions have been tested with high accuracy. As more genetic markers associated with diseases are identified, our ability to predict genetic disease will significantly increase. The era of PGD with deep sequencing is coming and will benefit more couples with genetic disorders or infertility problems. Additionally, PGD with deep sequencing also has the advantages of high sensitivity and specificity to detect both point mutations and aneuploidy, and it is cost efficient.

This work was supported by the Beijing Municipal Science and Technology Commission (Z131100005213006), the National Natural Science Foundation of China (31230047), and the National Basic Research Program of China (2011CB944504).

1 Handyside AH, Kontogianni EH, Hardy K, Winston RM. Pregnancies from biopsied human preimplantation embryos sexed by Y-specific DNA amplification. Nature, 1990, 344: 768-770

2 Rechitsky S, Verlinsky O, Chistokhina A, Sharapova T, Ozen S, Masciangelo C, Kuliev A, Verlinsky Y. Preimplantation genetic diagnosis for cancer predisposition. Reprod Biomed Online, 2002, 5: 148-155

3 Xu K, Shi ZM, Veeck LL, Hughes MR, Rosenwaks Z. First unaffected pregnancy using preimplantation genetic diagnosis for sickle cell anemia. JAMA, 1999, 281: 1701-1706

4 Kuliev A, Rechitsky S, Verlinsky O, Ivakhnenko V, Cieslak J, Evsikov S, Wolf G, Angastiniotis M, Kalakoutis G, Strom C, Verlinsky Y. Birth of healthy children after preimplantation diagnosis of thalassemias. J Assist Reprod Genet, 1999, 16: 207-211

5 Goossens V, Traeger-Synodinos J, Coonen E, De Rycke M, Moutou C, Pehlivan T, Derks-Smeets IA, Harton G. ESHRE PGD Consortium data collection XI: cycles from January to December 2008 with pregnancy follow-up to October 2009. Hum Reprod, 2012, 27: 1887-1911

6 Bingol B, Tasdemir S, Gunenc Z, Abike F, Esenkaya S, Tavukcuoglu S, Berkil H. Prenatal diagnosis of Comel-Netherton syndrome with PGD, case report and review article. J Assist Reprod Genet, 2011, 28: 615-620

7 Altarescu G, Barenholz O, Renbaum P, Beeri R, Levy-Lahad E, Margalioth EJ, Brooks B, Varshaver I, Eldar-Geva T. Preimplantation genetic diagnosis (PGD) - prevention of the birth of children affected with endocrine diseases. J Pediatr Endocrinol Metab, 2011, 24: 543-548

8 Simpson JL. Preimplantation genetic diagnosis at 20 years. Prenat Diagn, 2010, 30: 682-695

9 Berger VK, Baker VL. Preimplantation diagnosis for single gene disorders. Semin Reprod Med, 2014, 32: 107-113

10 Sermon K, van Steirteghem A, Liebaers I. Preimplantation genetic diagnosis. Lancet, 2004, 363: 1633-1641

11 Moutou C, Goossens V, Coonen E, De Rycke M, Kokkali G, Renwick P, Sengupta SB, Vesela K, Traeger-Synodinos J. ESHRE PGD Consortium data collection XII: cycles from January to December 2009 with pregnancy follow-up to October 2010. Hum Reprod, 2014, 29: 880-903

12 Jiang B, Tan AS, Chong SS. Molecular strategies for preimplantation genetic diagnosis of single gene and chromosomal disorders. Best Pract Res Clin Obstet Gynaecol, 2012, 26: 551-559

13 Donnelly LS, Watson M, Moynihan C, Bancroft E, Evans DG, Eeles $\mathrm{R}$, Lavery S, Ormondroyd E. Reproductive decision-making in young female carriers of a BRCA mutation. Hum Reprod, 2013, 28: 1006-1012

14 Sagi M, Weinberg N, Eilat A, Aizenman E, Werner M, Girsh E, Siminovsky Y, Abeliovich D, Peretz T, Simon A, Laufer N. Preim- plantation genetic diagnosis for BRCA1/2 - a novel clinical experience. Prenat Diagn, 2009, 29: 508-513

15 Chen YL, Hung CC, Lin SY, Fang MY, Tsai YY, Chang LJ, Lee CN, $\mathrm{Su}$ YN, Chen SU, Yang YS. Successful application of the strategy of blastocyst biopsy, vitrification, whole genome amplification, and thawed embryo transfer for preimplantation genetic diagnosis of neurofibromatosis type 1. Taiwan J Obstet Gynecol, 2011, 50: 74-78

16 Drusedau M, Dreesen JC, Derks-Smeets I, Coonen E, van Golde R, van Echten-Arends J, Kastrop PM, Blok MJ, Gomez-Garcia E, Geraedts JP, Smeets HJ, de Die-Smulders CE and Paulussen AD. PGD for hereditary breast and ovarian cancer: the route to universal tests for BRCA1 and BRCA2 mutation carriers. Eur J Hum Genet, 2013, 21: 1361-1368

17 Malcov M, Ben-Yosef D, Amit A, Yaron Y. Preimplantation genetic diagnosis (PGD) for cancer predisposition syndromes. Harefuah, 2011, 150: 496-501, 553

18 Schaefer AM, Taylor RW, Turnbull DM, Chinnery PF. The epidemiology of mitochondrial disorders-past, present and future. Biochim Biophys Acta, 2004, 1659: 115-120

19 Amato P, Tachibana M, Sparman M, Mitalipov S. Three-parent in vitro fertilization: gene replacement for the prevention of inherited mitochondrial diseases. Fertil Steril, 2014, 101: 31-35

20 Steffann J, Frydman N, Gigarel N, Burlet P, Ray PF, Fanchin R, Feyereisen E, Kerbrat V, Tachdjian G, Bonnefont JP, Frydman R, Munnich A. Analysis of mtDNA variant segregation during early human embryonic development: a tool for successful NARP preimplantation diagnosis. J Med Genet, 2006, 43: 244-247

21 Treff NR, Campos J, Tao X, Levy B, Ferry KM, Scott RJ. Blastocyst preimplantation genetic diagnosis (PGD) of a mitochondrial DNA disorder. Fertil Steril, 2012, 98: 1236-1240

22 Sallevelt SC, Dreesen JC, Drusedau M, Spierts S, Coonen E, van Tienen FH, van Golde RJ, de Coo IF, Geraedts JP, de Die-Smulders CE, Smeets HJ. Preimplantation genetic diagnosis in mitochondrial DNA disorders: challenge and success. J Med Genet, 2013, 50: 125-132

23 Tachibana M, Amato P, Sparman M, Woodward J, Sanchis DM, Ma H, Gutierrez NM, Tippner-Hedges R, Kang E, Lee HS, Ramsey C, Masterson K, Battaglia D, Lee D, Wu D, Jensen J, Patton P, Gokhale S, Stouffer R, Mitalipov S. Towards germline gene therapy of inherited mitochondrial diseases. Nature, 2013, 493: 627-631

24 Verlinsky Y, Rechitsky S, Schoolcraft W, Strom C, Kuliev A. Preimplantation diagnosis for Fanconi anemia combined with HLA matching. JAMA, 2001, 285: 3130-3133

25 Brezina PR. Preimplantation genetic testing in the 21st century: uncharted territory. Clin Med Insights Reprod Health, 2013, 7: 17-21

26 Bielorai B, Hughes MR, Auerbach AD, Nagler A, Loewenthal R, Rechavi G, Toren A. Successful umbilical cord blood transplantation for Fanconi anemia using preimplantation genetic diagnosis for HLA-matched donor. Am J Hematol, 2004, 77: 397-399

27 Verlinsky Y, Cieslak J, Freidine M, Ivakhnenko V, Wolf G, Kovalinskaya L, White M, Lifchez A, Kaplan B, Moise J, Et A. Pregnancies following pre-conception diagnosis of common aneuploidies by fluorescent in-situ hybridization. Hum Reprod, 1995, 10: 1923-1927

28 Rubio C, Simon C, Vidal F, Rodrigo L, Pehlivan T, Remohi J, Pellicer A. Chromosomal abnormalities and embryo development in recurrent miscarriage couples. Hum Reprod, 2003, 18: 182-188

29 Jiang B, Tan AS, Chong SS. Molecular strategies for preimplantation genetic diagnosis of single gene and chromosomal disorders. Best Pract Res Clin Obstet Gynaecol, 2012, 26: 551-559

30 Schoolcraft WB, Katz-Jaffe MG. Comprehensive chromosome screening of trophectoderm with vitrification facilitates elective single-embryo transfer for infertile women with advanced maternal age. Fertil Steril, 2013, 100: 615-619

31 Kaser DJ, Ginsburg ES. Embryo biopsy for aneuploidy detection in the general infertility population. Semin Reprod Med, 2014, 32: 100-106

32 Findlay I, Ray P, Quirke P, Rutherford A, Lilford R. Allelic drop-out and preferential amplification in single cells and human blastomeres: 
implications for preimplantation diagnosis of sex and cystic fibrosis. Hum Reprod, 1995, 10: 1609-1618

33 Thornhill AR, Snow K. Molecular diagnostics in preimplantation genetic diagnosis. J Mol Diagn, 2002, 4: 11-29

34 Renwick P, Ogilvie CM. Preimplantation genetic diagnosis for monogenic diseases: overview and emerging issues. Expert Rev Mol Diagn, 2007, 7: 33-43

35 Wells D, Sherlock JK. Strategies for preimplantation genetic diagnosis of single gene disorders by DNA amplification. Prenat Diagn, 1998, 18: 1389-1401

36 Harton GL, De Rycke M, Fiorentino F, Moutou C, SenGupta S, Traeger-Synodinos J, Harper JC. ESHRE PGD consortium best practice guidelines for amplification-based PGD. Hum Reprod, 2011, 26: 33-40

37 Collins SC. Preimplantation genetic diagnosis: technical advances and expanding applications. Curr Opin Obstet Gynecol, 2013, 25: 201-206

38 Rubio C, Bellver J, Rodrigo L, Bosch E, Mercader A, Vidal C, De Los SM, Giles J, Labarta E, Domingo J, Crespo J, Remohi J, Pellicer A, Simon C. Preimplantation genetic screening using fluorescence in situ hybridization in patients with repetitive implantation failure and advanced maternal age: two randomized trials. Fertil Steril, 2013, 99: 1400-1407

39 Munne S, Dailey T, Finkelstein M, Weier HU. Reduction in signal overlap results in increased FISH efficiency: implications for preimplantation genetic diagnosis. J Assist Reprod Genet, 1996, 13: 149-156

40 Velilla E, Escudero T, Munne S. Blastomere fixation techniques and risk of misdiagnosis for preimplantation genetic diagnosis of aneuploidy. Reprod Biomed Online, 2002, 4: 210-217

41 Colls P, Sandalinas M, Pagidas K, Munne S. PGD analysis for aneuploidy in a patient heterozygous for a polymorphism of chromosome 16 (16qh-). Prenat Diagn, 2004, 24: 741-744

42 Mir P, Rodrigo L, Mateu E, Peinado V, Milan M, Mercader A, Buendia P, Delgado A, Pellicer A, Remohi J, Rubio C. Improving FISH diagnosis for preimplantation genetic aneuploidy screening. Hum Reprod, 2010, 25: 1812-1817

43 Wells D, Delhanty JD. Comprehensive chromosomal analysis of human preimplantation embryos using whole genome amplification and single cell comparative genomic hybridization. Mol Hum Reprod, 2000, 6: 1055-1062

44 Handyside AH, Harton GL, Mariani B, Thornhill AR, Affara N, Shaw MA, Griffin DK. Karyomapping: a universal method for genome wide analysis of genetic disease based on mapping crossovers between parental haplotypes. J Med Genet, 2010, 47: 651-658

45 Le Caignec C, Spits C, Sermon K, De Rycke M, Thienpont B, Debrock S, Staessen C, Moreau Y, Fryns JP, Van Steirteghem A, Liebaers I, Vermeesch JR. Single-cell chromosomal imbalances detection by array CGH. Nucleic Acids Res, 2006, 34: e68

46 Simpson JL. Preimplantation genetic diagnosis to improve pregnancy outcomes in subfertility. Best Pract Res Clin Obstet Gynaecol, 2012, 26: $805-815$

47 Treff NR, Fedick A, Tao X, Devkota B, Taylor D, Scott RJ. Evaluation of targeted next-generation sequencing-based preimplantation genetic diagnosis of monogenic disease. Fertil Steril, 2013, 99: 1377-1384

48 Fiorentino F, Biricik A, Bono S, Spizzichino L, Cotroneo E, Cottone G, Kokocinski F, Michel CE. Development and validation of a next-generation sequencing-based protocol for 24-chromosome aneuploidy screening of embryos. Fertil Steril, 2014, 101: 1375-1382

49 Dean FB, Nelson JR, Giesler TL, Lasken RS. Rapid amplification of plasmid and phage DNA using Phi 29 DNA polymerase and multiply-primed rolling circle amplification. Genome Res, 2001, 11:
1095-1099

50 Ni X, Zhuo M, Su Z, Duan J, Gao Y, Wang Z, Zong C, Bai H, Chapman AR, Zhao J, Xu L, An T, Ma Q, Wang Y, Wu M, Sun Y, Wang S, Li Z, Yang X, Yong J, Su XD, Lu Y, Bai F, Xie XS, Wang J. Reproducible copy number variation patterns among single circulating tumor cells of lung cancer patients. Proc Natl Acad Sci USA, 2013, 110: 21083-21088

51 Lu S, Zong C, Fan W, Yang M, Li J, Chapman AR, Zhu P, Hu X, Xu L, Yan L, Bai F, Qiao J, Tang F, Li R, Xie XS. Probing meiotic recombination and aneuploidy of single sperm cells by whole-genome sequencing. Science, 2012, 338: 1627-1630

52 Hou Y, Fan W, Yan L, Li R, Lian Y, Huang J, Li J, Xu L, Tang F, Xie XS, Qiao J. Genome analyses of single human oocytes. Cell, 2013, 155: 1492-1506

53 Zong C, Lu S, Chapman AR, Xie XS. Genome-wide detection of single-nucleotide and copy-number variations of a single human cell. Science, 2012, 338: 1622-1626

54 Martin J, Cervero A, Mir P, Martinez-Conejero JA, Pellicer A, Simon C. The impact of next-generation sequencing technology on preimplantation genetic diagnosis and screening. Fertil Steril, 2013, 99: 1054-1061

55 Sulem P, Gudbjartsson DF, Stacey SN, Helgason A, Rafnar T, Magnusson KP, Manolescu A, Karason A, Palsson A, Thorleifsson G, Jakobsdottir M, Steinberg S, Palsson S, Jonasson F, Sigurgeirsson B, Thorisdottir K, Ragnarsson R, Benediktsdottir KR, Aben KK, Kiemeney LA, Olafsson JH, Gulcher J, Kong A, Thorsteinsdottir U, Stefansson K. Genetic determinants of hair, eye and skin pigmentation in Europeans. Nat Genet, 2007, 39: 1443-1452

56 Scott KL, Hong KH, Scott RJ. Selecting the optimal time to perform biopsy for preimplantation genetic testing. Fertil Steril, 2013, 100: 608-614

57 Mertzanidou A, Spits C, Nguyen HT, Van de Velde H, Sermon K. Evolution of aneuploidy up to day 4 of human preimplantation development. Hum Reprod, 2013, 28: 1716-1724

58 Mertzanidou A, Wilton L, Cheng J, Spits C, Vanneste E, Moreau Y, Vermeesch JR, Sermon K. Microarray analysis reveals abnormal chromosomal complements in over $70 \%$ of 14 normally developing human embryos. Hum Reprod, 2013, 28: 256-264

59 Chang LJ, Huang CC, Tsai YY, Hung CC, Fang MY, Lin YC, Su YN, Chen SU, Yang YS. Blastocyst biopsy and vitrification are effective for preimplantation genetic diagnosis of monogenic diseases. Hum Reprod, 2013, 28: 1435-1444

60 McArthur SJ, Leigh D, Marshall JT, de Boer KA, Jansen RP. Pregnancies and live births after trophectoderm biopsy and preimplantation genetic testing of human blastocysts. Fertil Steril, 2005, 84: 1628-1636

61 Rouen A, Hyon C, Balet R, Joye N, Cassuto NG, Siffroi JP. First birth after sperm selection through discontinuous gradient centrifugation and artificial insemination from a chromosomal translocation carrier. Case Rep Genet, 2014, 2014: 906145

62 Gutierrez-Mateo C, Sanchez-Garcia JF, Fischer J, Tormasi S, Cohen J, Munne S, Wells D. Preimplantation genetic diagnosis of single-gene disorders: experience with more than 200 cycles conducted by a reference laboratory in the United States. Fertil Steril, 2009, 92: 1544-1556

63 Wilton L, Thornhill A, Traeger-Synodinos J, Sermon KD, Harper JC. The causes of misdiagnosis and adverse outcomes in PGD. Hum Reprod, 2009, 24: 1221-1228

64 Mir P, Rodrigo L, Mercader A, Buendia P, Mateu E, Milan-Sanchez M, Peinado V, Pellicer A, Remohi J, Simon C, Rubio C. False positive rate of an arrayCGH platform for single-cell preimplantation genetic screening and subsequent clinical application on day-3. J Assist Reprod Genet, 2013, 30: 143-149

Open Access This article is distributed under the terms of the Creative Commons Attribution License which permits any use, distribution, and reproduction in any medium, provided the original author(s) and source are credited. 